\title{
Práticas corporais de saúde para pacientes com fibromialgia: acolhimento e humanização
}

\author{
I 1 Leonardo Hernandes de Souza Oliveira, ${ }^{2}$ Rafael da Silva Mattos, \\ ${ }^{3}$ Juliana Brandão Pinto de Castro, ${ }^{4}$ Madel Therezinha Luz I
}

Resumo: A fibromialgia é uma síndrome reumática que atinge principalmente mulheres, chegando a acometer cerca de $2 \%$ da população brasileira, sendo caracterizada principalmente por dor musculoesquelética crônica e difusa e por 11 de 18 pontos dolorosos à palpação. $\mathrm{O}$ diagnóstico é predominantemente clínico e marcado pela ausência de substrato anatômico, confrontando a racionalidade médica ocidental. As práticas corporais de saúde vêm sendo utilizadas como terapêutica não farmacológica para pacientes com fibromialgia. $\mathrm{O}$ objetivo desta pesquisa foi analisar o acolhimento e a humanização do cuidado nas práticas corporais de saúde para mulheres diagnosticadas com fibromialgia participantes do programa de extensão "Práticas Corporais de Saúde" (PRACORSAU), da Universidade do Estado do Rio de Janeiro. Foram realizadas entrevistas abertas com oito mulheres diagnosticadas com fibromialgia. A metodologia de análise dos dados usada baseou-se na obra $A$ ordem do discurso, de Foucault. Constatou-se, através das falas das mulheres, que o PRACORSAU acolhe e promove o vínculo entre as mulheres que integram as atividades. Todas as pessoas que chegam a um serviço de saúde devem ter a necessidade identificada e obter uma resposta imediata à sua situação. $\mathrm{O}$ acolhimento precisa ser reconhecido, pelos profissionais, como um instrumento para reestruturar e redefinir a atenção em saúde.

> Palavras-chave: fibromialgia; práticas corporais de saúde; acolhimento.

\author{
1 Programa de Pós-Graduação em \\ Ciências do Exercício e do Esporte \\ do Instituto de Educação Física \\ e Desportos da Universidade do \\ Estado do Rio de Janeiro. Rio de \\ Janeiro-RJ, Brasil (Ihernandes. \\ uerj@gmail.com). \\ 2 Programa de Pós-Graduação \\ em Ciências do Exercício e \\ do Esporte do Instituto de \\ Educação Física e Desportos da \\ Universidade do Estado do Rio de \\ Janeiro. Rio de Janeiro-RJ, Brasil \\ (profmattos2010@gmail.com). \\ ${ }^{3}$ Programa de Pós-Graduação \\ em Ciências do Exercício e \\ do Esporte do Instituto de \\ Educação Física e Desportos da \\ Universidade do Estado do Rio \\ de Janeiro. Rio de Janeiro-RJ, \\ Brasil (julianabrandaoflp@ \\ hotmail.com). \\ ${ }^{4}$ Programa de Pós-Graduação \\ em Saúde Coletiva. \\ Universidade Federal do Rio \\ Grande do Sul. Porto Alegre-RS, \\ Brasil (madelluzz@gmail.com).
}

Recebido em: 25/09/2016 Aprovado em: 15/06/2017 
O presente estudo faz parte da pesquisa "Praticas corporais de saúde e fibromialgia”, que está sendo desenvolvida em um programa de pós-graduação e em um programa de extensáo com o objetivo de compreender os sentidos atribuídos às práticas corporais de saúde por pacientes diagnosticados com fibromialgia. Práticas corporais de saúde estão sendo utilizadas como terapêutica não farmacológica para pacientes com fibromialgia (MATTOS, 2015; MATTOS; LUZ, 2012; GONÇALVES et al., 2010; LUZ, 2011; LUZ, 2005).

A fibromialgia é uma síndrome reumática de origem desconhecida com prevalência de $2 \%$ na população brasileira. É caracterizada principalmente por dor musculoesquelética crônica e difusa. Está associada com frequência a um conjunto de sinais e sintomas, como a fadiga generalizada, a rigidez matinal, distúrbios do sono, dores de cabeça, ansiedade, distúrbios do humor, depressão e dispneia (MARTINEZ et al., 2017; MATTOS; LUZ, 2012; ÁLVARES; LIMA, 2010; GONÇALVES et al., 2010; CAVALCANTE et al., 2006; SANTOS et al., 2006; STAUD, 2004; YUNUS, 1994).

A prevalência da fibromialgia varia entre $0,66 \%$ e $4,4 \%$, na população mundial, sendo responsável por aproximadamente $15 \%$ das consultas ambulatoriais de reumatologia e 5\% a 10\% nos ambulatórios de clínica geral. Levando em consideração o Brasil, a síndrome acomete cerca de $2 \%$ da populaçáo (CAVALCANTE et al., 2006; MATTOS; LUZ, 2012; GONÇALVES et al., 2010; PROVENZA et al., 2004). De acordo com alguns autores, a fibromialgia ataca principalmente as mulheres (MATTOS; LUZ, 2012; ALVARES; LIMA, 2010; CAVALCANTE et al., 2006; BRASIO et al., 2003).

A Medicina tradicional encara a doença a partir de um ponto de vista biológico apenas, não levando em conta os determinantes sociais da saúde e a subjetividade do mal-estar. Nesse sentido, a biomedicina se fundamenta nas pesquisas científicas biológicas com testes estatísticos, protocolos e procedimentos que qualificam o sintoma como verdadeiro ou falso. A verdade da cura limita-se à cura da doença cientificamente definida. Frequentemente, a biomedicina diminui a influência da cultura nos processos de dor, explicando seus mecanismos apenas por questóes neurosensitivas.

Segundo Martinez et al. (2017), a teoria fisiopatológica mais aceita é que se trata de uma síndrome de amplificação dolorosa com alteração no processamento 
da nocicepção no tocante ao sistema nervoso central. Associa-se também a uma resposta anormal aos estressores habituais do cotidiano evidenciada por alterações no eixo hipotálamo-hipofisário-adrenal.

As explicaçóes para o adoecimento também são construídas a partir de hipóteses genéticas individuais, o que reforça a biologização da causalidade das doenças e da mudança comportamental como forma de "adquirir" saúde ou prevenir agravos. É negligenciado o fato de que pessoas estejam adoecendo e em consequência de processos que não estão diretamente conectados com a assistência à saúde, como falta de saneamento básico, sobrecarga de trabalho, poluição ambiental, entre outros determinantes (MATTOS; LUZ, 2012; LUZ, 2005; 2011; TESSER, 2007; MORETTI et al., 2009; GOMES; PINHEIRO, 2005).

A necessidade de acolher as pessoas com doenças crônicas surgiu das discussôes sobre a reorientação da atenção à saúde. Coutinho et al. (2015) realizaram uma revisão integrativa sobre o acolhimento nos âmbitos da atenção primária à saúde e da estratégia de saúde da família. $\mathrm{O}$ acolhimento é muito mais que uma atitude de escuta qualificada. É um compromisso com a responsabilidade do cuidado, a resolutividade dos problemas e com os encaminhamentos necessários.

O acolhimento é um ato de inclusão, uma atitude que busca a universalidade e a integralidade, princípios do SUS, no tratamento dos usuários de saúde. Trata-se de um "estar com" ou "estar perto de" (BRASIL, 2010). É uma das diretrizes da Política Nacional de Humanização do Sistema Único de Saúde (SUS) e não deve ser encarado como um espaço ou local, mas como uma postura ética que não supóe hora ou profissionais específicos para fazê-lo, pois implica compartilhamento de saberes, angústias e invençóes, ao tomar para si a responsabilidade de acolher as pessoas em suas demandas (FERREIRA et al., 2014).

O acolhimento leva em consideração três princípios: atender a todas as pessoas que buscam os serviços de saúde, garantindo a acessibilidade universal; reorganizar o processo de trabalho, deslocando seu eixo central do médico para uma equipe interdisciplinar; qualificar a relaçấo profissional de saúde/usuário a partir de parâmetros humanitários de solidariedade e de cidadania (BAIÃO et al., 2014).

A questão central do presente estudo é analisar o acolhimento e a humanização nas práticas corporais para mulheres diagnosticadas com fibromialgia participantes de um Programa de Extensão denominado "Práticas Corporais de Saúde" (PRACORSAU), em uma universidade pública brasileira. 


\section{As práticas corporais de saúde}

Bourdieu (1983) apresenta o conhecimento praxiológico, um nível de conhecimento que inclui a prática como elemento básico das açóes dos sujeitos. Esse conhecimento permite a superaçáo das cisóes entre estrutura e sujeito, objetividade e subjetividade, macro e microanálise com a síntese teórica. Ao mesmo tempo que as práticas são irredutíveis à racionalidade, elas se apoiam em um conjunto de teorias.

O conhecimento praxiológico proposto por Bourdieu articula dialeticamente a estrutural social e o ator social, sendo a mediaçáo entre agente social e sociedade o problema central desse nível de pensamento. A vida social é objetiva e antecede a você, à família, à classe social, que representam formas estáveis de estruturação, estruturantes nas práticas. As práticas reproduzem essas formas, o habitus (BOURDIEU, 1983).

Segundo Bourdieu (1983), o habitus orienta as açóes e, na medida em que é o produto das relaçôes sociais, assegura a reprodução dessas mesmas relaçôes objetivas que o engendraram.

Sistemas de disposiçōes duráveis, estruturas estruturadas predispostas a funcionar como estruturas estruturantes, isto é, como princípio gerador e estruturador das práticas e das representações que podem ser objetivamente "reguladas" ou "regulares" sem ser o produto da obediência às regras, objetivamente adaptadas a um fim, sem que se tenha necessidade da projeção consciente deste fim ou do domínio das operaçôes para atingi-lo, mas sendo, ao mesmo tempo, coletivamente orquestradas sem serem o produto da ação organizadora de um maestro (BOURDIEU, 1983, p. 15).

A adequação entre o habitus e essa situação permite fundar uma teoria da prática que leve em consideração tanto as necessidades dos agentes quanto a objetividade da sociedade. A prática, conjunçáo do habitus e da situação, ocorre no seio de um espaço que transcende as relaçóes entre os atores. A prática é resultado de um aparecimento de um habitus. O habitus produz as práticas, pois é um princípio gerador de estratégias (BOURDIEU, 1983).

As práticas corporais de saúde são "caminhos" que as pessoas percorrem na busca por cuidado e atenção. Os indivíduos não estão buscando estas práticas apenas para resolver problemas do mundo contemporâneo relacionados com o adoecimento, sofrimento, isolamento e vulnerabilidade; é mais que isso, eles estão buscando também a recuperação das suas identidades, a reinserção 
social ou familiar e principalmente a autonomia diante de um acometimento (CARVALHO, 2006; LUZ, 2005).

Dentro do contexto das práticas corporais de saúde, o movimento humano é compreendido como sendo dotado de valores, desejos, sentidos e significados socioculturais, sendo constituído por fatores que ultrapassam o modelo biologizante. São práticas que podem ser referenciadas nas Ciências Sociais e Humanas, visando criar novos discursos em relação à terapêutica (SILVA et al., 2008; LUZ, 2005; CARVALHO, 2006). As práticas corporais de saúde precisam estar relacionadas à descoberta e à consciência corporal, aos sentidos e significados do cuidar. Em outras palavras, são componentes da cultura corporal dos povos, vinculadas ao movimento humano e aos modos de se expressar pelo corpo.

$\operatorname{Luz}(2005 ; 2011)$ entende a globalização como um processo de desenvolvimento do capitalismo e concentração de capital em nível mundial que causa exclusão e deterioração social, principalmente, nas sociedades periféricas, gera instabilidade e a insegurança social, provocando níveis maiores de adoecimento da população.

A compreensão da realidade social contemporânea depende tanto de um aspecto econômico quanto de um aspecto socioantropológico. Levando em consideraçáo a perspectiva econômica, o mundo está submetido às leis e regras de uma economia capitalista globalizada, em sua quarta revolução tecnológica, que, por sua vez, influencia a dimensão socioantropológica, causando acirramento de valores, como individualismo, consumismo, competitividade e busca crescente pela dominação do outro e da natureza, o que vem provocando uma gradativa concentração mundial de riqueza, reproduzindo as desigualdades sociais mesmo em países tidos como ricos, posto que nos mesmos as taxas de acumulação de renda são maiores que as de crescimento econômico (MATTOS, 2015; PIKETTY, 2014; CARVALHO; LUZ, 2009; LUZ, 2005).

Valores e significados voltados para competição profissional individualizada são difundidos de modo consciente ou inconsciente. A solidão advinda da ausência de solidariedade, depressão, ansiedade e a fibromialgia podem estar presentes nas vidas das pessoas devido aos altos níveis de estresse, que advém dessas condiçóes socioeconômicas e culturais vigentes. Todo esse contexto gera mal-estar coletivo, uma síndrome coletiva de natureza biopsíquica que pode repercutir na saúde física e mental da população. Longe de querer estabelecer uma relação causal com a fibromialgia, faz-se necessário ressaltar que esse mal- 
estar coletivo é caracterizado por dores difusas, depressão, ansiedade, pânico e males da coluna vertebral.

Por atuarem no processo de cuidar do corpo, proporcionando solidariedade e uma rede de sociabilidade, resolvendo os problemas relacionados ao adoecimento e sofrimento da população, as práticas corporais de saúde tornamse um caminho para os pacientes com fibromialgia. Segundo Mattos (2015), os pacientes experimentam uma sensação de acolhimento, de atenção, encontrando pessoas que conseguem reconhecer o sofrimento causado pela síndrome. $\mathrm{O}$ acolhimento, nas unidades de saúde, favorece a construção de uma relação de confiança e compromisso dos usuários com as equipes e com os serviços, contribuindo para a legitimação do sistema público de saúde, essencial para a população (FERREIRA et al., 2014).

\section{Métodos}

A pesquisa empreendida é de natureza qualitativa e a coleta de dados foi realizada através de entrevistas com usuárias de saúde do PRACORSAU, do Instituto de Educaçáo Física e Desportos (IEFD) da Universidade do Estado do Rio de Janeiro (UERJ). A UERJ oferece tratamento interdisciplinar para pacientes com fibromialgia no IEFD desde 2000, com a intenção de proporcionar terapêutica não medicamentosa.

O PRACORSAU oferece práticas corporais supervisionadas por profissionais de Educação Física em duas sessôes semanais de uma hora cada (terças e quintas), orientaçáo nutricional quinzenal e apoio psicológico semanal por profissionais habilitados, em parceria com a Policlínica Piquet Carneiro e o Hospital Universitário Pedro Ernesto.

As atividades são gratuitas e para ingressar basta ter encaminhamento de um médico e avaliação cardiológica que inclua teste ergométrico. As práticas corporais privilegiam exercícios aeróbicos lúdicos, treinamento de força, de flexibilidade e atividades cooperativas. As principais atividades desenvolvidas são: caminhadas, circuitos, atividades com bambolês, com bolas, com cordas, danças, gincanas, estafetas e ginásticas.

Participaram do presente estudo oito usuárias de saúde, com uma média de idade de 55,25 $\pm 8,90$ anos, que frequentaram as atividades interdisciplinares do PRACORSAU em 2015. Todas assinaram um Termo de Consentimento Livre e 
Esclarecido (TCLE) e a pesquisa foi aprovada pelo Comitê de Ética e Pesquisa do Hospital Universitário Pedro Ernesto (CEP-HUPE). O critério de inclusão para a participação na pesquisa foi ter ingressado no PRACORSAU em 2015 e ter no mínimo seis meses de participação das atividades, com $75 \%$ de presença. As entrevistas foram realizadas no IEFD da UERJ, localizado na rua São Francisco Xavier n ${ }^{\circ} .524,8^{\circ}$ andar, sala 8.114, Bloco F. Cada entrevista teve duração média de 50 minutos.

A metodologia de análise das entrevistas foi a Análise da Ordem do Discurso, como discutido por Foucault (1971). A ordem do discurso foi a aula inaugural de Michel Foucault no Collège de France, no dia 2 de dezembro de 1970. Para o autor, todo discurso tem quatro princípios metodológicos: inversão, descontinuidade, especificidade e exterioridade. Privilegiamos o princípio da exterioridade na interpretação das entrevistas.

Este princípio coloca o discurso diante das suas condiçôes externas e não do seu centro. Trata-se de compreender o aparecimento dos saberes a partir de condiçóes de possibilidades externas aos próprios saberes. Os saberes são situados como peças de relaçóes de poder. Analisar entrevistas à luz do princípio de exterioridade é levar em consideração os fatores externos que montam/constituem o discurso.

O discurso constitui-se de conjuntos de enunciados sustentados em formaçôes discursivas que pertencem a um mesmo conjunto de regras e leis. Assim, o discurso consiste em uma prática ou conjunto de práticas que definem e formam os objetos de que falam, ou seja, são as palavras que fornecem significados às coisas. Portanto, é por meio de nomeaçôes, descriçóes e concepçôes que construímos conhecimentos e podemos agir sobre nós mesmos e sobre os outros (FOUCAULT, 1971).

Segundo Santos e Souza (2015), a contribuição de Michel Foucault para a Análise do Discurso é demonstrar que os sujeitos não são a causa nem a origem dos discursos, pois são seres sociais constituídos a partir do entrelaçar dos diversos discursos que os circulam socialmente. Há uma exterioridade do discurso e não uma lógica interna baseada em intencionalidades. Quem fala se posiciona por um estatuto, um lugar de onde fala, o qual está articulado aos lugares institucionais ocupados (LEMOS et al., 2015).

Britos (2003) afirma que Foucault propóe uma análise da relação entre discurso e ação que consiste em assinalar que a ordem do discurso instala uma 
nova problematização das práticas discursivas. Com isso, é possível interrogar quais mecanismos de estabilização das políticas de verdade consolidam as formaçôes discursivas. Mais que indagar sobre as condições de possibilidade do discurso, interessa a Foucault compreender estratégias de emergência daquilo que se põe como a verdade. $\mathrm{O}$ dito pelos entrevistados não é a verdade ou uma mera construção cultural da verdade, mas sim uma expressão das estratégias de saberpoder que atravessa os sujeitos.

\section{Acolhimento e humanização nas práticas corporais}

O PRACORSAU, ao oferecer tratamento interdisciplinar para pacientes diagnosticados com fibromialgia, vem se constituindo ao longo dos últimos dezessete anos como importante local de atenção à saúde nos moldes da territorialização do SUS. A territorialização em saúde consiste na organização de serviços e ações de saúde com uma delimitação espacial e social determinada e uma população adscrita. Pessoas de diversos municípios do Estado do Rio de Janeiro procuram o PRACORSAU.

A descentralização é um dos princípios organizativos do SUS. Descentralizar é transferir autoridade, competência, responsabilidades e tomada de decisões para melhorar a gestão e a resolutividade do sistema de saúde. A descentralização implica responsabilizar o nível local de gestão pelos serviços prestados à população de um território.

Correa et al. (2017) afirmam que a integralidade está relacionada à ideia de saúde como direito de cidadania, logo, à humanização das práticas em saúde, associando as exigências técnicas aos interesses e necessidades de indivíduos e coletividades. No âmbito setorial, a integralidade precisa ser construída em cada unidade de saúde e na rede integrada e regionalizada de atenção.

A regionalização com base territorial e populacional busca uma distribuição das açôes de saúde que promovam equidade do acesso, qualidade, otimização dos recursos e racionalidades dos gastos. Assim, a ideia de territorialização do cuidado se efetua com uma população específica em um espaço definido com problemas de saúde próprios. O PRACORSAU é um programa constituído pelo conceito de atenção básica à saúde, isto é, um conjunto de ações de saúde, no âmbito individual e coletivo, que abrange a promoção e a proteção da saúde, a prevenção de agravos, o diagnóstico, o tratamento e a manutenção da saúde (BRASIL, 2012). 
Vale ressaltar que a falta de acesso aos serviços públicos às mulheres é uma forma de violência e discriminação, conforme a "Convenção Internacional sobre a eliminação de todas as formas de discriminação contra a mulher” adotada, em 1979, pela Organização das Nações Unidas (ONU). Qualquer restrição ou exclusão baseada no gênero é violação internacional dos direitos humanos e das liberdades fundamentais. Ademais, o Brasil ratificou a "Convenção Interamericana para Prevenir, Punir e Erradicar a Violência contra a Mulher” adotada pela Assembleia Geral da Organização dos Estados Americanos (OEA), em 1994.

Costa et al. (2007) ressaltam que o Programa de Atenção Integral à Mulher (PAISM) foi gestado no contexto da Reforma Sanitária brasileira a partir dos movimentos sociais, que apontavam para a necessidade de cuidado universal e

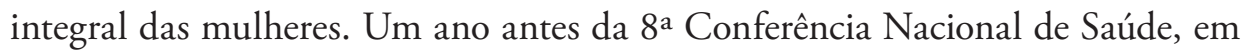
Brasília, em 1986, foi criado o Conselho Nacional de Direitos da Mulher. Em 1987, foi publicada a Carta das Mulheres Brasileiras aos Constituintes.

Segundo Ferreira (2016), a saúde da mulher representa um desafio e uma prioridade para a rede de atenção à saúde. O SUS frequentemente percebe a mulher de forma tradicional e focaliza os aspectos reprodutivos, não acolhendo mulheres lésbicas, transexuais, prostitutas, carcerárias, mulheres em situação de violência ou com vulnerabilidade socioeconômica naquelas particularidades que ultrapassam a reprodução e o controle da sexualidade. Rodrigues et al. (2017) destacam que a população brasileira é constituída por $51,4 \%$ de mulheres, sendo as principais usuárias do SUS e que buscam atendimento para filhos, netos, marido, idosos e vizinhos, esquecendo-se, muitas vezes, do seu próprio cuidado, tornando-se vulnerável às doenças.

Em 2004, foi instituída a Política Nacional de Humanização (PNH), com o propósito de promover a integralidade das ações de saúde. Trata-se de um conjunto de açóes para reduzir as filas e o tempo de espera com ampliaçáo de acesso e atendimento acolhedor e resolutivo; assegurar que todos os usuários do SUS conheçam os profissionais que cuidam de sua saúde; garantir aos usuários o acesso às informaçóes e à presença de acompanhante de sua livre escolha em todos os momentos do cuidado de sua saúde (BRASIL, 2004a; BRASIL, 2004b).

O Ministério da Saúde (BRASIL, 2004a) define humanização como um conjunto de princípios e diretrizes que se traduzem em açôes nos diversos serviços, nas práticas de saúde, caracterizando uma construçáo coletiva dos 
profissionais de saúde para acolher com qualidade o usuário. A humanização em saúde supóe que sejam ultrapassadas as fronteiras dos diferentes núcleos de saber/ poder que se ocupam da produção da saúde e que uma visão interdisciplinar prevaleça com ênfase no cuidado. Humanizar é ofertar um atendimento de qualidade, articulando os avanços em tecnologia com o acolhimento dos usuários. Humanizar não é "tornar humano" na acepção metafísica, mas sim adotar condutas e atitudes diferenciadas que acolham as pessoas que estão sofrendo e procuram um serviço de saúde.

De acordo com Correa et al. (2017), o acolhimento remete à relação ofertademanda, escuta dos relatos objetivos e subjetivos das vivências dos usuários, afetividade e visão mais apurada na busca constante de identificar e atender às necessidades de saúde e comunicação dialógica. Indica o caráter crítico e reflexivo do agir profissional, que busca a superação de uma prática clínica reduzida a protocolos padronizados.

O acolhimento é um modo de operar os processos de trabalho em saúde de forma a atender todos que procuram os serviços de saúde, ouvindo seus pedidos e assumindo uma postura capaz de acolher, escutar e dar respostas adequadas aos usuários. Requer uma escuta com responsabilizaçáo e resolutividade. O acolhimento não é um ato isolado, mas um dispositivo atitudinal dentro da perspectiva das redes de atenção à saúde e do conceito ampliado de saúde (BRASIL, 2013).

O conceito ampliado de saúde compreende todo processo de saúde-doença como o resultante das condições de alimentação, habitação, educação, renda, meio ambiente, trabalho, transporte, emprego, lazer, liberdade, acesso e posse da terra e acesso aos serviços de saúde. É o resultado das formas de organização social e de produção que podem gerar desigualdades nos níveis de vida. Esse conceito ampliado de saúde privilegia o modelo de atenção básica à saúde e não o modelo hospitalocêntrico-curativo. $\mathrm{O}$ acolhimento, a humanização, as linhas de cuidado, os projetos terapêuticos singulares e outras estratégias solidificam a proposta de um sistema único de saúde predominantemente preventivo e comprometido com a promoção da saúde.

A humanização é então uma estratégia de interferência no processo de produção da saúde que investe na criação de um novo tipo de interação entre os sujeitos que constituem os sistemas de saúde e deles usufruem, acolhendo tais 
atores e promovendo seu protagonismo. A solidariedade e os laços de cidadania são destacados, pois é uma estratégia que leva em consideração a singularidade de cada sujeito (BRASIL, 2004a).

Para Sena et al. (2015), o acolhimento é uma das vertentes mais visíveis da Política Nacional de Humanização na Atenção Primária à Saúde. Segundo o Ministério da Saúde (BRASIL, 2004b) o acolhimento é uma ação tecnoassistencial que pressupóe a mudança da relação profissional/usuário e sua rede social através de parâmetros técnicos, éticos, humanitários e de solidariedade, reconhecendo o usuário como sujeito e participante ativo no processo de produção da saúde.

É possível identificar através da fala de algumas usuárias de saúde que o PRACORSAU, por meio das atividades que promove, acolhe e fomenta o vínculo entre as mulheres que integram as atividades. Os laços sociais são formados entre as usuárias que frequentam o Programa Práticas Corporais de Saúde. Quando questionada sobre o que mais gostou no Programa, uma das usuárias de saúde respondeu:

\footnotetext{
Além do exercício, a amizade, o carinho que todas têm uma pelas outras. As meninas do projeto também trabalham com muita atenção, carinho também, os meninos também trabalham assim (sic) (60 anos, viúva, costureira, São Gonçalo).

[...] é uma união, o carinho que as estagiárias têm com a gente, partindo de todos vocês, a professora e tudo, quer dizer, é muito carinhoso, eu sinto orgulho de tá participando, e acho que por isso que estou botando foco, muita fé e coragem e tô sentindo melhora e noto que tenho que tá lá com o remedinho direitinho também (60 anos, viúva, costureira, São Gonçalo).
}

As falas em destaque corroboram o posicionamento de Gomes e Pinheiro (2005) a respeito do acolhimento. Os autores o conceituam como relação humanizada que pode ocorrer entre os prestadores de serviço e os pacientes. Para Girão e Freitas (2016), o acolhimento promove a criação e a consolidação de vínculos, na medida em que os usuários passam a se sentir acolhidos pelo serviço.

O vínculo é uma prática social de humanização nos serviços de saúde. Incentiva o cuidado e induz a responsabilização de ambas as partes pela promoção da saúde. Percebemos que se multiplicam os grupos sociais que praticam atividades de saúde buscando romper o isolamento social que se instalou com a consolidaçáo do capitalismo, intensificando-se nas relaçôes sociais do último quarto do século XX. A questão da ausência crescente de solidariedade, do vazio causado pela angústia 
presente em grande parte da população devido ao modo de produção capitalista, à divisão social do trabalho ou ao racionalismo burocratizante é tema central na obra dos clássicos das Ciências Sociais, sendo ainda questão crucial contemporânea (SUDO et al., 2011; SOUZA; LUZ, 2009; CARVALHO; LUZ, 2009).

Em Marx (2013), o trabalhador, ao lidar com a produção de mercadorias, acaba por se ver como tal e perceber as relaçōes sociais como relaçôes entre coisas que podem ser compradas, o que produz para ele o fetichismo da mercadoria. Em Durkheim (2002), o individualismo e o crescente esgarçamento moral produzido pelas relaçôes cada vez mais aprimoradas de produção de bens conduzem as sociedades atuais ao estado de anomia, ou anormalidade funcional, e, por fim, Weber (1982), ao estudar o crescente racionalismo do capitalismo com sua burocratização detalhada e crescente no controle da vida cotidiana, cunha o conceito de desencantamento do mundo. Todos estes três clássicos ressaltam desse processo a perda do sentido da existência por parte das pessoas nas sociedades contemporâneas.

Esse sentimento de vazio é cultural e psicológico, representando a perda de sentidos, de significados, de investimentos nas relaçóes sociais (CUNHA, 2013). É o desencantamento com a sociabilidade. Segundo Luz (2005), as pessoas estão buscando práticas corporais coletivas de saúde diversas (ginástica em academias, exercícios de tai-chi-chuan nas praças, alongamento, hidroginástica, dança de salão, entre outras) tentando reencantar a vida. Trata-se da multiplicação da busca por práticas de saúde por grupos e coletividades.

Alguns autores (ROCHA; SPAGNUOLO, 2015; MITRE et al., 2012) reconhecem o importante papel do acolhimento no cenário nacional, sendo uma estratégia que induz modificaçóes organizacionais, melhorando o acesso, o trabalho em equipe e a relação entre o prestador de serviço e o usuário.

O princípio da exterioridade, apresentado por Foucault (1971), ressalta que, de alguma forma, esses discursos são construídos a partir de condiçôes externas. Em algum momento, as perdas familiares e as experiências prévias e negativas com outros serviços públicos podem ter influenciado na constituição discursiva.

[...] meu esposo faleceu de câncer no estômago, aí já fiquei sofrendo por isso e na luta com meus dois meninos. Ai quando fez 7 meses que meu marido morreu, o outrozinho morreu com 13 anos, agora ia tá com 25, que morreu teve 7 meses depois foi dia 11/03, ai quando foi agora em abril passado fez 3 anos, vai fazer 4 anos em abril que vem que faleceu o outro, quer dizer, no mesmo mês vai fazer 32 anos (60 anos, viúva, costureira, São Gonçalo). 
Para Mattos (2015), é a partir do acolhimento, do vínculo e da atenção que os pacientes com fibromialgia conseguem encontrar pessoas que reconhecem o sofrimento causado pela síndrome. Uma das usuárias entrevistadas deixa isso muito claro a partir do seu discurso:

Aqui todo mundo tem a mesma coisa, então todo mundo se entende! Os sintomas da gente vão se encaixando, aí quando a gente fala sobre isso com as pessoas que não tem fibromialgia, as pessoas ficam olhando com cara de deboche (sic) (64 anos, casada, aposentada, Rio de Janeiro).

O vínculo é a relação de cumplicidade entre usuários e profissionais de saúde, que se concretiza a partir do acolhimento, sendo o ponto de partida para a construção de confiança entre os envolvidos (GIRÃO; FREITAS, 2016). O vínculo é o alicerce constitutivo dos processos de produção de saúde (BRASIL, 2010).

Mattos (2015) entende que os sintomas da fibromialgia, enquanto um discurso, formam uma linguagem social entre as mulheres. Essa mesma linguagem, formada e compartilhada ao longo do tratamento com práticas corporais, desencadeia o vínculo e o sentimento de pertencimento. Essa construção de uma identidade coletiva de grupo possibilita ao paciente uma nova maneira de lidar com o sofrimento.

Esse grupo, ele todo é importante, é um grupo que identifica, que identifica a gente, entendeu? É um grupo que fala a mesma linguagem [...] (57 anos, casada, enfermeira, Rio de Janeiro).

[...] esse grupo aqui é excelente. Esse grupo, nossa atividade física também é muito boa (57 anos, casada, enfermeira, Rio de Janeiro).

Ahh... totalmente diferente, pois você está lidando com pessoas que tem o mesmo problema que você, que entende o que você está falando. Quando você fala que não conseguiu fazer as tarefas de casa, aquela pessoa vai entender porque também acontece com ela. Por isso que a gente acha que encontra esse apoio aqui no grupo, a gente se sente mais (sic) (47 anos, casada, recepcionista/telefonista, Rio de Janeiro).

Os trechos destacados anteriormente ressaltaram a importância do grupo no contexto da atividade física. A crença no grupo parece ser um ponto interessante, principalmente quando os membros apresentam as mesmas particularidades. Segundo Fragoso e Negrine (1997), a crença no grupo, o carinho, o afeto, o contato e o respeito mútuo são motivaçóes que levam as pessoas a se identificarem com as práticas corporais. Parece que as duas usuárias de saúde encontraram finalmente um grupo capaz de reconhecer parte do sofrimento causado pela síndrome. 
As práticas corporais de saúde possibilitam a criação e/ou ampliação do vínculo entre os sujeitos históricos e destes com os trabalhadores e serviços de saúde (CARVALHO, 2016). Os benefícios proporcionados pelas práticas corporais vão além da prevenção de doenças crônicas não transmissíveis, pois não estão atrelados apenas aos benefícios biológicos que, de certa forma, são hegemônicos. Por outro lado, este processo pode sugerir uma nova forma da sociedade civil se organizar, buscando cunhar novos sentidos e significados, novas estratégias de sobrevivência diante das opressóes sistêmicas, conforme ressaltam Sabino e Luz (2011), quando destacam que esse processo pode ser tanto individual (pertencer ao registro da individuação, para usar um termo menos metafísico, já que é o indivíduo o cerne do processo), como coletivo; com alta ou baixa carga de reflexividade, diversos níveis de subjetividade (ou subjetivação) e intencionalidade (DOMINGUES, 1999; 2004).

Carvalho e Luz (2009) citam os dois paradigmas que orientam as práticas: o clássico e o da vitalidade. Aquele reproduz concepçôes hegemônicas dos saberes fragmentados e especializados das disciplinas médicas, reforçando a cisão natureza/cultura, sujeito/objeto, corpo/mente. Esse opera nos campos da integralidade e da vitalidade, compreendendo a saúde não apenas como ausência de doenças e utilizando racionalidades médicas predominantemente orientais. Apesar de não haver fronteiras entre esses dois paradigmas, as usuárias de saúde entrevistadas ressaltaram características do paradigma da vitalidade presente nas práticas corporais:

[...] a professora, as estagiárias, os estagiários nos tratam com respeito e com carinho, respeitam nossos limites quando falamos que estamos com muitas dores, pois eles falam para gente sentar e relaxar; então há respeito, carinho, atenção (47 anos, casada, recepcionista/telefonista, Rio de Janeiro).

Quando você tem uma atenção, você tem até melhora. Atenção é tudo, e amor, né $(s i c)$ ? (60 anos, casada, técnico de laboratório, Rio de Janeiro).

As práticas corporais de saúde oferecidas pelo PRACORSAU podem ter identificado as necessidades afetivas das usuárias de saúde. As duas usuárias relataram, durante as entrevistas, dificuldades em encontrar um serviço de saúde capaz de solucionar demandas. Enquanto uma usuária relatou que os serviços públicos de saúde negavam atendimento por não conhecerem a fibromialgia, a outra usuária destacou que os tratamentos em que estava inserida não resolviam seus problemas. 
Os usuários de determinado serviço de saúde revelam suas particularidades no momento em que se sentem acolhidos (BARBOSA et al., 2014) e, segundo Silva e Romano (2015), o acolhimento possibilita a identificação das necessidades dos usuários. Levando em consideração o posicionamento dos autores, parece que as práticas corporais acolheram as usuárias de saúde junto com suas reais necessidades. Para Lopes et al. (2015), o acolhimento deve existir em todas as relaçôes de cuidado.

Os autores Mitre et al. (2013) evidenciaram, a partir de um estudo sobre o acolhimento nos Centros de Referências em Reabilitação da Rede do SUS, que o modelo biomédico, quando presente nas concepçóes dos profissionais de saúde, pode limitar a atuação dos mesmos no que diz respeito ao acolhimento, comprometendo a participação e autonomia dos usuários. Nesse modelo, a patologia determinará a trajetória do usuário nos serviços de saúde, excluindo-o da construção do seu próprio projeto terapêutico. A diretriz do acolhimento reconhece o usuário enquanto sujeito da produção do cuidado, ressaltando os benefícios da interdisciplinaridade.

O discurso de grande parte das usuárias de saúde entrevistadas confirma o importante papel das práticas corporais no tratamento para pessoas com fibromialgia. Algumas usuárias chegaram a relatar que foi a primeira vez que encontraram um grupo que fala a mesma "língua", sendo a primeira vez que se identificaram com um grupo. No ambiente de trabalho e nas conversas com familiares, esse vínculo não foi estabelecido:

No trabalho isso não existia, esse tipo de relação mais próxima. Para falar de fibromialgia, é porque eu também sou assim, eu não gosto de pedir ajuda. Mesmo reclamona eu não gosto de falar com as pessoas, pois acaba sendo um falar sem retorno, né? (sic) (57 anos, casada, enfermeira, Rio de Janeiro).

Em casa eu sou a chata, a reclamona, aquela mãe chata, aquela mulher chata [...] (57 anos, casada, enfermeira, Rio de Janeiro).

A falta de compreensão tanto no lar, quanto nas atividades laborais, é destacada por essas mulheres. Não existe um diálogo, pois se consolida um falar sem retorno. As pessoas que convivem com essas mulheres de certa forma não compreendem os sintomas e muito menos o sofrimento que a fibromialgia causa na vida dos indivíduos acometidos. Todas essas experiências prévias negativas podem ter influenciado o discurso sobre as práticas corporais, principalmente no que se diz respeito ao acolhimento e ao vínculo. 
Eu me encontrei aqui, porque a gente fala e as pessoas não entendem, meu esposo mesmo, meu esposo não entende quando estou com dor. Mas as meninas sentem e então a gente fala a mesma língua. Eu me encontrei aqui e gostei muito, eu gostei muito da oportunidade que eu tive aqui, da oportunidade de fazer parte desse grupo (sic) (53 anos, casada, estudante, Rio de Janeiro).

Agora, quando você conversa com outras pessoas, é lógico, elas tentam entender, até se esforçam para entender, mas náo é a mesma coisa conversar com pessoas que têm problemas e pessoas que não têm (sic) (53 anos, casada, estudante, Rio de Janeiro).

O acolhimento deve existir em todas as relaçôes de cuidado e na prática de receber e principalmente escutar pessoas. É uma ferramenta que possibilita a humanização do cuidado; amplia o acesso da populaçáo aos serviços de saúde; coordena os serviços; e vincula a efetivação de relaçôes entre usuários e profissionais de saúde (LOPES et al., 2015).

Eu acho muito bom, inclusive quando eu não venho eu sinto falta, tipo assim, eles nos acolhem né [...] (47 anos, casada, recepcionista/telefonista, Rio de Janeiro).

O acolhimento daqui é bem forte, porque a história de uma bate com a da outra, aí a gente vai se entendendo, pois é o lugar onde a gente consegue enxergar que tem outras pessoas que sentem as mesmas dores e os mesmos sintomas, porque lá fora, lá fora do grupo é difícil a pessoa entender (sic) (38 anos, casada, do lar, Rio de Janeiro).

Durante as entrevistas, algumas usuárias relataram as experiências que tiveram em outros centros/programas terapêuticos. A prática de receber e principalmente de escutar pessoas foi exercida também por alguns profissionais da Policlínica Piquet Carneiro:

O diferencial dela é que ela te escuta, ela te ouve, você fala o que sente e ela te dá uma atenção, ela presta atenção naquilo que você está falando e procura te ajudar da melhor maneira possível. Tenta te ajudar com os remédios se você não estiver se sentindo bem [...] (47 anos, casada, recepcionista/telefonista, Rio de Janeiro).

A prática da escuta foi evidenciada e parece que uma clínica adequada foi estabelecida, pois o profissional da Policlínica colocou em plano a situação real do trabalho em saúde vivida pela usuária de saúde. A Clínica Ampliada convida a uma ampliação do objeto de trabalho para que pessoas se responsabilizem por pessoas (BRASIL, 2009).

As pacientes com fibromialgia demandam resolutividade por parte dos sistemas de atendimento em saúde. As entrevistas mostram mulheres ativas que cobram uma capacidade resolutiva, de resolver ou finalizar um processo. Essas demandas podem ser entendidas como esperanças que as usuárias têm em 
relação ao sistema de saúde para que os seus problemas sejam solucionados. Uma das usuárias entrevistadas expôs a sua história de vida afirmando que os médicos de antigamente eram melhores, pois tinham uma capacidade resolutiva melhor:

Muito, muito melhores! Você ia ao médico e no mesmo instante o médico colocava na agenda dele o dia que você tinha que voltar, eles te davam o papel, você era atendido se voltasse lá, você não ficava nesse vai e vêm, vai para o UPA, vai para não sei aonde. Eu fui no Miguel Couto segunda e o rapaz só bateu o raio x, depois me pediu a ressonância, mas aí eu perguntei se eu não podia fazer a ressonância lá, o médico respondeu que lá não tinha, mas eu duvidei disso, porque hoje em dia você tem que duvidar das coisas (64 anos, casada, aposentada, Rio de Janeiro).

A cobrança por um sistema de atendimento em saúde capaz de solucionar reivindicaçôes pode ter tido na Constituição Federal de 1988 uma inspiração. Segundo o artigo 196, a saúde é direito de todos e dever do Estado, garantido mediante políticas sociais e econômicas que visem à redução do risco de doença e de outros agravos e ao acesso universal e igualitário às açóes e serviços para sua promoção, proteção e recuperação.

Para as autoras Schmidt e Figueiredo (2009), o acolhimento é o primeiro contato com quem procura o serviço, a partir do qual será definida toda a sequência de atendimentos. É nesse momento que todos os recursos do serviço são colocados à prova: quem atende; o que pode oferecer; como pode acolher. $\mathrm{Na}$ realidade, o acolhimento é uma técnica que promove a utilização do saber profissional para produzir respostas ao usuário.

Segundo Barbosa et al. (2014), os usuários de determinado serviço de saúde revelam suas particularidades no momento em que se sentem acolhidos. Acolher é encontrar outra forma de lidar com o singular. Quando os casos não são devidamente acolhidos, as situaçôes diversas são mais difíceis de serem encaradas. $\mathrm{O}$ acolhimento possibilita a identificação das necessidades reais dos usuários (SILVA; ROMANO, 2015).

No PRACORSAU, todas as usuárias de saúde têm acesso à nutrição, psicologia e atividade física. Todas essas atividades foram enaltecidas positivamente pelas usuárias entrevistadas:

[...] aqui me ensinou bem a me conhecer mais, não só na parte do exercício, mas também na alimentação, a menina que é a nutricionista daqui sempre tem umas dicas muito boas. Tem a parte da psicologia que tem uma professora muito boa também (65 anos, casada, técnico de enfermagem, Rio de Janeiro). 
[...] o exercício físico ajuda, a palestra com a psicóloga e a nutrição também ajudam muito. A nutrição ajuda muito porque ela dá uma base em relação às coisas que a gente tem que comer, a gente está em casa fazendo as coisas e não assimila [...] (65 anos, casada, técnico de enfermagem, Rio de Janeiro).

Girão e Freitas (2016) também destacam a importância das atividades interdisciplinares para a produção do cuidado, construção do vínculo e promoção da saúde. A interdisciplinaridade pode possibilitar uma corresponsabilidade entre usuários e trabalhadores de saúde.

O princípio da exterioridade sustenta a ideia de que as condiçóes externas influenciam o "falar" dessas mulheres. Em inúmeros momentos, as usuárias entrevistadas ressaltaram o sentimento de pertencimento (acolhimento) e os laços sociais que foram consolidados (vínculo) com as práticas corporais de saúde.

\section{Considerações finais}

O objetivo do presente estudo foi analisar o acolhimento e a humanização do cuidado nas práticas corporais para mulheres diagnosticadas com fibromialgia participantes do Programa de Extensão PRACORSAU.

O acolhimento é uma das diretrizes de maior relevância da Política Nacional de Humanização do SUS e, por isso, é relevante compreender como ele ocorre nos diversos serviços de saúde. Neste artigo, focalizamos um olhar mais centrado na perspectiva sociocultural e procuramos ressaltar aspectos poucos considerados na biomedicina tradicional.

Nos estudos sobre as práticas corporais de saúde, as Ciências Sociais têm contribuído não apenas com técnicas qualitativas, mas sobretudo com o olhar disciplinar dessas ciências, centrado na compreensão e na interpretaçẫo dos fenômenos socioculturais ligados à saúde e ao adoecimento. Uma boa terapêutica, humana e acolhedora, consistiria em uma resposta ao sofrimento do paciente que procura o serviço de saúde, e em um cuidado para que o paciente não seja visto apenas como aparelho ou sistema biológico.

O cuidado está presente no encontro, na conversa, na atitude do profissional de saúde que busca prudentemente reconhecer, para além das demandas explícitas, as necessidades dos cidadãos no que diz respeito a sua saúde. O cuidado está presente também na preocupação dos profissionais com a promoção da saúde, a prevenção de doenças e agravos e não apenas nas açôes curativas. O cuidado não 
é uma forma de regulação dos corpos, mas um caminho para a integralidade da atenção e da efetividade do sistema de saúde.

As atividades lúdicas, cooperativas e coletivas oferecidas pelo PRACORSAU podem ter produzido alguns novos sentidos para a saúde e para a vida social das usuárias de saúde. Por compreender o movimento humano dotado de valores, desejos e significados socioculturais, as práticas corporais de saúde fizeram com que as usuárias de saúde experimentassem o acolhimento e o vínculo. Motta e Marchiori (2013) ressaltam que práticas corporais terapêuticas aplicadas a pacientes com fibromialgia podem proporcionar elementos que a biomedicina negligencia, como a dimensão dos sentidos e a relação com o corpo e a doença, propiciando aos participantes novos valores por meio da gestualidade e da consciência corporal, estimulando o autoconhecimento corporal e o reencontro do sujeito consigo.

Deve ser levado em consideração também o custo social que a saúde passou a representar, devido à deterioração psicossocial característica da globalização, fazendo com que a instabilidade e a insegurança proporcionem um maior nível de estresse, gerando o adoecimento da população. Todo esse contexto produz um grande mal-estar psicossocial e coletivo, identificado por dores difusas, depressão e ansiedade (MORETTI et al., 2009; LUZ, 2005).

Todas as pessoas que chegam a um serviço de saúde devem ter sua necessidade reconhecida, bem como obter uma resposta imediata a sua situação. Para isso, os profissionais precisam reconhecer o acolhimento como um instrumento para reestruturar e redefinir a atenção em saúde (NEVES et al., 2013). ${ }^{1}$

\section{Referências}

ÁlVARES, T. T.; LIMA, M. E. A. Fibromialgia: interfaces com as LER/DORT e consideraçôes sobre sua etiologia ocupacional. Ciência e Saúde Coletiva, v. 15, n. 3, p. 803812, 2010.

BAIÂO, B. S. et al. Acolhimento humanizado em um posto de saúde urbano no Distrito Federal, Brasil. Revista APS, v. 17, n. 3, p. 291-302, 2014.

BARBOSA, L. B.; DIMENSTEIN, M.; LEITE, J. F. Mulheres, violência e atenção em saúde mental: questôes para (re)pensar o acolhimento no cotidiano dos serviços. Avances em Psicología Latinoamerican. Bogotá, v. 32, n. 2, p. 309-320, 2014.

BOURDIEU, P. Sociologia. São Paulo: Ática, 1983.

BRASIL. Constituição da república federativa do Brasil. Brasília: Senado, 1988. 
BRASIL. Ministério da Saúde. Departamento de Atenção Básica, Secretaria de Atenção à Saúde, Ministério da Saúde. Política Nacional de Atenção Básica. Brasília: Ministério da Saúde, 2012.

- Secretaria de Atenção à Saúde. Departamento de Atenção Básica. Diretrizes para o cuidado das pessoas com doenças crônicas nas redes de atenção à saúde e nas linhas de cuidado prioritárias. Brasília: Ministério da Saúde, 2013.

. Secretaria de Atenção à Saúde. Núcleo Técnico da Política Nacional de Humanização. Acolhimento nas Práticas de Produção de Saúde. 2. ed. Brasília: Ministério da Saúde, 2010.

- Secretaria de Atenção à Saúde. Política Nacional de Humanização da Atenção e Gestão do SUS. Humaniza SUS: clínica ampliada e compartilhada. Brasília: Ministério da Saúde, 2009.

Secretaria-Executiva. Núcleo Técnico da Política Nacional de Humanização. Humaniza SUS: a humanização como eixo norteador das práticas atenção e gestão em todas as instâncias do SUS. Brasília: Ministério da Saúde, 2004a.

Secretaria Executiva. Núcleo Técnico da Política Nacional de Humanização. Humaniza SUS: acolhimento com avaliação e classificação de risco: um paradigma ético-estético no fazer em saúde. Brasília: Ministério da Saúde, 2004 b.

BRASIO, K. M. et al. Comparação entre três técnicas de intervenção psicológica para tratamento da fibromialgia: treino de controle de stress, relaxamento progressivo, e reestruturação cognitiva. Revista de Ciências Médicas. Campinas, v. 12, n. 4, p. 307-318, 2003.

BRITOS, M. P. Michel Foucault: Del orden del discurso a una pragmática de lo múltiple. Tópicos. Santa Fe, n. 11, p. 63-82, 2003.

CARVALHO, F. F. B. Práticas corporais e atividades físicas na Atenção Básica do Sistema Único de Saúde: ir além da prevenção das doenças crônicas não transmissíveis é necessário. Movimento. Porto Alegre, v. 22, n. 2, p. 647-658, 2016.

CARVALHO, M. C. V. S.; LUZ, M. T. Práticas de saúde, sentidos e significados construídos: instrumentos teóricos para sua interpretação. Interface - Comunicação, Saúde, Educação, v. 13, n. 29, p. 313-326, 2009.

CARVAlHO, Y. M. Promoção da saúde, práticas corporais e atenção básica. Revista Brasileira Saúde da Família, n. 11, p. 33-45, 2006.

CAVAlCANTE, A. B. et al. A prevalência de fibromialgia: uma revisão de literatura. Revista Brasileira de Reumatologia, v. 46, n. 1, p. 40-48, 2006.

CORREA, M. S. M. et al. Atención en el cuidado a la salud de la mujer durante el puerperio. Cadernos de Saúde Pública, v. 33, n. 3, p. 1-12, 2017.

COSTA, A. M. et al. A saúde da mulher e o SUS: laços e diversidades no processo de formulação, implementação e avaliação das políticas de saúde para mulheres no Brasil. Saúde em Debate, v. 31, n. 75-77, p. 13-24, 2007. 
COUTINHO, L. R. P.; BARBIERI, A. R.; SANTOS, M. L. M. Acolhimento na atenção primária à saúde: revisão integrativa. Saúde em Debate. Rio de Janeiro, v. 39, n. 105, p. 514524, 2015.

CUNHA, M. P. Uma nota sobre o mal-estar na modernidade. Clinica \& Cultura, v. 2, n. 2, p. 13-24, 2013.

DOMINGUES, J. M. Ensaios de sociologia: Teoria e pesquisa. Belo Horizonte: Ed. UFMG. 2004.

. Criatividade social, subjetividade coletiva e a modernidade brasileira contemporânea. Rio de Janeiro: Contracapa Livraria, 1999.

DURKHEIM, E. Liçôes de Sociologia. São Paulo: Martins Fontes, 2002.

FERREIRA, M. L. S. M.; PENQUES, R. M. V. B.; MARIN, M. J. S. Acolhimento na percepção dos enfermeiros da Atenção Primária à Saúde. Aquichan. Colômbia (Chia), v. 14, n. 2, p. 217-225, 2014.

FERREIRA, J. Integralidade na Rede de Atenção à Saúde da Mulher: uma vivência na região da grande Florianópolis. Anais do VI SEPE: Seminário de Ensino, Pesquisa e Extensão da UFFS, v. 6, n. 1, 2016.

FOUCAULT, M. L'ordre du discours. Paris: Gallimard, 1971.

FRAGOSO, R.; NEGRINE, A. Práticas corporais alternativas e seus significados. Movimento. Porto Alegre, v. 4, n. 6, p. 14-33, 1997.

GIRÃO, A. L. A.; FREITAS, C. H. A. Usuários hipertensos na atenção primária à saúde: acesso, vínculo e acolhimento à demanda espontânea. Revista Gaúcha de Enfermagem, v. 37, n. 2, p. 1-7, 2016.

GOMES, M. C.P. A.; PINHEIRO, R. Acolhimento e vínculo: práticas de integralidade na gestão do cuidado em saúde em grandes centros urbanos. Interface - Comunicação, Saúde e Educação. Botucatu, v. 9, n. 17, p. 287-301, 2005.

GONÇALVES, T. R. et al. Evasão de um programa de tratamento multidisciplinar para mulheres com fibromialgia. Revista Brasileira em Promoção da Saúde. Fortaleza, v. 23, n. 1, p. 63-68, 2010.

LEMOS, F. C. S. et al. Notas sobre a genealogia e a pesquisa cartográfica. ECOS - Estudos Contemporâneos da Subjetividade, v. 5, n. 2, p. 209-218, 2015.

LOPES, A. S. et al. O acolhimento na Atenção Básica em saúde: relações de reciprocidade entre trabalhadores e usuários. Saúde Debate, v. 39, n. 104, p. 114-123, 2015.

LUZ, M. T. Novos saberes e Práticas em Saúde Coletiva: estudo sobre racionalidades médicas e atividades corporais. 2. ed. rev. São Paulo: Hucitec, 2005.

Especificidade da contribuição dos saberes e práticas das ciências sociais e humanas para a saúde. Saúde e Sociedade, v. 20, n. 1, p. 22-31, 2011. 
MARTINEZ, J. E.; BOLOGNA, S. C.; EL-KADRE, J. M. R. Há correlação entre o grau de resiliência e o impacto da fibromialgia na qualidade de vida? Revista da Faculdade de Ciências Médicas de Sorocaba, v. 19, n. 1, p. 6-9, 2017.

MARX, K. O Capital. Crítica da economia política. Livro 1. O processo de produção do capital. São Paulo: Boitempo, 2013.

MATTOS, R. S. Fibromialgia: o mal-estar do século XXI. São Paulo: Phorte, 2015.

MATTOS, R. S.; LUZ, M. T. Quando a perda de sentidos no mundo do trabalho implica dor e sofrimento: um estudo de caso sobre fibromialgia. Physis: Revista de Saúde Coletiva. Rio de Janeiro, v. 22, n. 4, p. 1.459-1.484, 2012.

MITRE, S. M.; ANDRADE, E. I. G.; COTTA, R. M. M. Avanços e desafios do acolhimento na operacionalização e qualificação do Sistema Único de Saúde na Atenção Primária: um resgate da produção bibliográfica do Brasil. Ciência \& Saúde Coletiva, v. 17, n. 8, p. 2.071-2.085, 2012.

. O acolhimento e as transformaçôes na práxis da reabilitação: um estudo dos Centros de Referência em Reabilitação da Rede do Sistema Único de Saúde em Belo Horizonte, MG, Brasil. Ciência \& Saúde Coletiva, v. 18, n. 7, p. 1.893-1.902, 2013.

MORETTI, A. C. et al. Práticas corporais/atividade física e políticas públicas de promoção da saúde. Saúde e Sociedade, v. 18, n. 2, p. 346-354, 2009.

MOTTA, P. M. R.; MARCHIORI, R. Racionalidades médicas e práticas integrativas em saúde: estudos teóricos e empíricos. Cadernos de Saúde Pública. Rio de Janeiro, v. 29, n. 4, p. 834-835, 2013.

NEVES, M.; PRETTO, S. M.; ELY, H. C. Percepçóes de usuários e trabalhadores de saúde sobre a implantação do acolhimento em uma unidade de saúde em Porto Alegre-RS, Brasil. Revista de Odontologia da UNESP. Porto Alegre, v. 42, n. 5, p. 364-371, 2013.

PIKETTY, T. O Capital no Século XXI. São Paulo: Intrínseca, 2014.

PROVENZA, J. R. et al. Fibromialgia. Revista Brasileira de Reumatologia, v. 44, n. 6, p. 443-449, 2004.

ROCHA, S.A.; SPAGNUOLO, R.S. Acolhimento na visão complexa: ação coletiva emergente na Equipe de Saúde da Família. Saúde e Debate, v. 39, n. 104, p. 123-135, 2015.

RODRIGUES, R. C. et al. Construção de instrumento para assistência à saúde da mulher na atenção primária à saúde. Saúde. Santa Maria, v. 43, n. 1, p. 1-9, 2017.

SABINO, C.; LUZ, M. Espelho da alma: teoria social e subjetivação em um conto de Machado de Assis. Physis: Revista de Saúde Coletiva. Rio de Janeiro, v. 21, n. 1, p. 237-250, 2011.

SANTOS, A. M. B. et al. Depressão e qualidade de vida em pacientes com fibromialgia. Revista Brasileira de Fisioterapia, v. 10, n. 3, p. 317-324, 2006. 
SANTOS, I.; SOUZA, M. A. O discurso em Foucault. Revista Pólen, v. 1, n. 1, p. 55-63, 2015.

SCHMIDT, M. B.; FIGUEIRIEDO, A. C. Acesso, acolhimento e acompanhamento: três desafios para o cotidiano da clínica em saúde mental. Revista Lationoamericana de Psicopatologia Fundamental, v. 12, n. 1, p. 130-140, 2009.

SENA, A. L. C. et al. Acolhimento e satisfação do usuário na estratégia de saúde da família: uma experiência. Revista de APS, v. 18, n. 2, p. 132-140, 2015.

SILVA, C. L.; VELOSO, E. L.; RODRIGUES JUNIOR, J. C. Pesquisa qualitativa em Educação Física: possibilidades de construção de conhecimento a partir do referencial cultural. Educação em Revista, n. 48, p. 37-60, 2008.

SILVA, T. F.; ROMANO, V. F. O acolhimento e o Núcleo de Apoio à Saúde da Família no município do Rio de Janeiro: fragmentos, perspectivas e reflexóes. Revista Brasileira de Medicina de Familia e Comunidade. Rio de Janeiro, v. 10, n. 44, p. 1-7, 2015.

SOUZA, E. F. A. A.; LUZ, M. T. Bases socioculturais das práticas terapêuticas alternativas. História, Ciências, Saúde-Manguinhos, v. 16, n. 2, p. 393-405, 2009.

STAUD, R. Fibromyalgia pain: do we know the source? Current Opinion Rheumatology, v. 16, n. 2, p. 157-163, 2004.

SUDO, N.; FERREIRA, J.; LUZ, M. T. Sentidos e significados do corpo ao longo do tempo: uma contribuição ao tema. Revista Ceres (On-line), v. 5, n. 2, p. 101-112, 2011.

TESSER, C. D. A verdade na biomedicina, reaçóes adversas e efeitos colaterais: uma reflexão introdutória. Physis: Revista de Saúde Coletiva. Rio de Janeiro, v. 17, n. 3, p. 465-484, 2007. WEBER, M. Ensaios de Sociologia. Rio de Janeiro: Zahar, 1982.

YUNUS, M. B. Psychological aspects of fibromyalgia syndrome: a component of the dysfunctional spectrum syndrome. Baillière's Clinical Rheumatology, v. 8, n. 4, p. 811-837, 1994.

\section{Nota}

${ }^{1}$ L. H. S. Oliveira e R. S. Mattos participaram igualmente da coleta e interpretação dos dados, redação e aprovação da versão final do artigo. J. B. P. de Castro participou da revisão técnica e teórica do texto e da formatação para as normas da revista. M. T. Luz realizou a revisão teórico-conceitual e metodológica do artigo. 
Corporal health practices for patients with
fibromyalgia: reception and humanization Fibromyalgia is a rheumatic syndrome that affects mainly women, reaching about $2 \%$ of the Brazilian population, being characterized mainly by chronic and diffuse musculoskeletal pain and 11 of 18 painful points to palpation. The diagnosis is predominantly clinical and marked by the absence of anatomical substrate, confronting Western medical rationality. The corporal health practices have been used as non-pharmacological therapy for patients with fibromyalgia. This research aimed to analyze the reception and humanization of care in the corporal health practices for women diagnosed with fibromyalgia participating in the extension program "Corporal Health Practices" (PRACORSAU), of Rio de Janeiro State University, Brazil. Open interviews were conducted with eight women diagnosed with fibromyalgia. The data analysis methodology used was based on Foucault's work The Order of Speech. It was verified, through the statements of the women, that PRACORSAU welcomes and promotes the bond between the women who integrate the activities. All people who arrive at a health service must have the identified need and get an immediate response to their situation. Reception must be recognized by professionals as an instrument to restructure and redefine health care.

> Keywords: fibromyalgia; corporal practices of health; user embracement. 